\title{
GOVERNMENT VERSUS PRIVATE OWNERSHIP OF PUBLIC GOODS*
}

\author{
Timothy Besley and Maitreesh GhataK
}

There has been a dramatic change in the division of responsibility between the state and the private sector for the delivery of public goods and services in recent years with an increasing trend toward contracting out to the private sector and "public-private partnerships." This paper analyzes how ownership matters in public good provision. We show that if contracts are incomplete then the ownership of a public good should lie with a party that values the benefits generated by it relatively more. This is true regardless of whether this party is also the key investor, or other aspects of the technology.

\section{INTRODUCTION}

The last twenty years have witnessed a dramatic change in the division of responsibility between the state and the private sector for the delivery of public goods and services. As evidence of weaknesses of in-house government provision has accumulated [World Bank 1995], there has been a global trend toward greater involvement of the private sector. ${ }^{1}$ This has often involved contracting out to both nonprofit organizations and for-profit firms, while maintaining state ownership. In other cases, ownership of public facilities by the private sector, or more complex forms of arrangements often referred to as "private-public partnerships" have been encouraged. Some economists, such as Shleifer [1998], have questioned whether there is at all a case for state ownership, even if social goals are taken into account, when the opportunities for government contracting are exploited.

From the seminal work of Grossman and Hart [1986] and Hart and Moore [1990] (henceforth, GHM), it is now appreciated that incomplete contracting provides a useful foundation for understanding the importance of ownership of firms. ${ }^{2}$ In this paper we extend these models to consider ownership issues for public

* We thank the editor, Edward Glaeser, two anonymous referees, Abhijit Banerjee, Pranab Bardhan, Eli Berman, Maitreya Ghatak, Semanti Ghosh, Oliver Hart, Karla Hoff, Raul Hopkins, Alain de Janvry, Joseph Kabowski, Michael Kremer, Andreas Lehnert, David Lewis, Dilip Mookherjee, John Moore, Abhinay Muthoo, Andrew Newman, Rohini Pande, Priya Ranjan, Debraj Ray, Elizabeth Sadoulet, Rani Spiegler, and numerous seminar participants for helpful comments and suggestions. The usual disclaimer applies.

1. For a careful microlevel empirical study of the relative efficiency of government agencies, for-profit firms, and nonprofit organizations, see the recent study of U. S. hospitals by Duggan [2000].

2. See Hart [1995] for a lucid discussion of the issues.

๑ 2001 by the President and Fellows of Harvard College and the Massachusetts Institute of Technology.

The Quarterly Journal of Economics, November 2001 
goods. Doing so, we obtain insights about ownership structure that diverge from the standard private goods case. ${ }^{3}$ In particular, we show that if the value created by the investments of the parties constitutes a public (i.e., nonrival and nonexcludable) good then the party with the highest valuation should be the owner irrespective of the relative importance of the investments or other aspects of the production technology. ${ }^{4}$

We motivate our analysis by the need to understand whether the government or private organizations should own public projects. Many states now delegate responsibility for providing social welfare and development services to nongovernmental organizations (henceforth, NGOs). Moreover, partnerships between governments and NGOs are frequently observed in Asian and Latin American countries (e.g., Farrington and Bebbington [1993], Fiszbein and Lowden [1999], and Farrington and Lewis [1993]).

Our key insights also apply to many other situations where parties share responsibilities in public good provision. Examples include collaborations between different government agencies (e.g., at the local and federal levels), or different private organizations for the provision of public goods. The analysis is also relevant for understanding collaborations in the fields of scientific research and art, and political campaigns. We also consider implications for assigning custody of children in divorce settlements.

Our baseline model is of a government and an NGO, each of whom can invest in a project that will increase the value of its service, which is a public good to the two parties. ${ }^{5}$ However, since the investments are noncontractible, the usual holdup problem arises, leading to underinvestment in the project. We then ask who should own the asset to maximize the net surplus generated by the investments. We show that, in a broad range of cases, this

3. The reason for the departure from the main results of GHM regarding ownership presented here is distinct from others that have been put forward in the private goods case (e.g., De Meza and Lockwood [1998] and Rajan and Zingales [1998]).

4. Hart, Shleifer, and Vishny [1997] also discuss the issue of public versus private ownership, but in their model at least one party does not directly care about the project, and hence ownership is governed by technological factors. See subsection III. 3 for a detailed discussion.

5 . While NGOs are typically not-for-profit, our analysis goes through as long as the organization directly cares about the project. This includes for-profit firms caring about, say, local education, culture, or the environment. See Glaeser and Shleifer [1998] for a recent paper that shows if the manager of a firm and customers share a taste for the quality of the service offered, not-for-profit status is likely to provide better incentives than for-profit status. However, they do not focus on ownership issues. 
will be the party that has the greatest valuation of the project. This conclusion departs from the standard presumption, due to Grossman and Hart [1986] and Hart and Moore [1990], that the ownership of an asset depends on the relative importance of the investment of the parties involved, and in particular, if there is a single investor, then she should own the asset. The model also explains why privately owned facilities funded by government investment are becoming increasingly popular.

The following example illustrates our basic argument. Suppose that a government agency (henceforth, the government) is deciding how much to invest in improving the quality of a school. There are two possible levels of investment, high and low, with costs 2 and 0 , respectively. The payoffs to the government from these two investment levels are 1 and 0 . Assume that an educational NGO is active in the community and, because it values the well-being of the children very highly, has payoffs from these investments of 5 and 0 . We also assume that the NGO has cash, but lacks a technology for investing in school quality. Hence, it has to rely on government as an investor. Finally, we suppose that the parties cannot contract on the level of investment or realized quality.

Joint government-NGO surplus is highest when the high level of investment is chosen. However, since the level of investment is not contractible, this cannot be guaranteed by an up-front payment from the NGO to the government. Similarly, since the quality of the school is not contractible, a promise by the NGO to make a transfer to the government if the quality of the school improves will not be kept. Following the incomplete contracting literature, assume that the parties bargain over the surplus after the investment is sunk, and the choice of investment depends upon the share of the surplus received by the investing party. Ownership affects the disagreement payoffs of the parties, hence their share of the surplus and investment incentives. If the government owns the school and chooses the high investment level, then in the event of disagreement, the government will continue with the project (since its ex post payoff is $1>0$ ), and the NGO will receive a payoff of 5 . Hence, the NGO cannot be induced to contribute anything to the project ex post, and ex ante the government will prefer the low level of investment.

If the NGO owns the school, both parties receive disagreement payoffs of zero since the investment needs the government's continued participation to generate any surplus. Bargaining 
therefore results in each receiving half of the surplus from the project. ${ }^{6}$ The government will now choose the higher level of investment as this will generate a net ex ante payoff of $3-2=$ 1 compared with zero under the low investment. Hence, NGO ownership yields the joint surplus maximizing level of investment in this example. Thus, investment incentives are better when ownership of the school is granted to the more caring party (the NGO) rather than the party with the investment technology (the government).

In the Grossman-Hart-Moore theory of the firm, ownership improves bargaining power and, hence, investment incentives. This is not true when the project is a public good. In the above example, the NGO has greater bargaining power when the government is the owner of the project since it values quality improvements whether or not it is directly involved. When the NGO is the owner, its bargaining advantage is lower as it cannot finish the project on its own. Hence, it is willing to transfer resources to the government. This has favorable ex ante investment incentives for the government. The fact that how much a party values the project and not the efficiency of its investment technology determines ownership undercuts the efficiency argument that is often made against government ownership. At the same time, it gives a reason why an NGO might be involved as an owner. In the paper we generalize this argument. We show that even when both parties invest in the project, and in the event of disagreement, the marginal return to the project from the investment of a party is higher when she is the owner, the investment incentives of both parties are higher when the party with the higher valuation is the owner.

The remainder of the paper is organized as follows. In the next section we lay out the basic model and present the main result. Various extensions and caveats are considered in Section III. Section IV reviews some applications of the model, with special emphasis on the experience of NGO involvement in public projects in developing countries. Section V concludes.

6. We are assuming that ownership cannot be costlessly transferred in the postinvestment stage. Otherwise, the NGO could abandon the ownership of the project, expecting the government to finish it. This would bring us back to the previous case, and ownership would not matter for investment. See Section II for more on this issue. 


\section{The Model}

There is a single time period in which a public project can be carried out. Two players, $g$ and $n$, can undertake human capital investments that will increase the benefits generated by the project (e.g., through improved quality). These investments can be interpreted as knowledge or project-specific skills that are not fully transferable to others in the absence of the investor. ${ }^{7}$ The project is "public" in the sense that the benefits that it generates (as distinct from the nonhuman assets associated with the project, or the investments themselves) are nonrival and nonexcludable to $g$ and $n$. Let $Y=\left(y_{g}, y_{n}\right)$ denote the vector of investment decisions.

Examples of the investments that we have in mind are specialized training, information acquisition, and developing a trusting relationship between staff and beneficiaries. The projects are such things as designing and running a school or health care system, teaching self-employment skills to beneficiaries of antipoverty programs, building an extension system to serve farmers, organizing groups for conservation projects, and developing monitoring and screening technologies for microlending programs.

It is key to the analysis that the human capital investments are specific to the project and lose value if employed in alternative uses. We will be specific about this below. The benefit from the project depends upon the investment level and is denoted by $b(Y)$. We assume that $b\left(y_{g}, y_{n}\right)$ is a smooth, increasing, and concave function satisfying the Inada endpoint conditions. In addition, we assume that $b(0,0)>0$ and $\partial^{2} b\left(y_{g}, y_{n}\right) / \partial y_{g} \partial y_{n} \geq 0$; i.e., investments are (weak) complements.

The two players value the project to different degrees, and payoffs are quasi-linear in project valuation and money. If $g$ contributes $C_{g}$ to the project's costs, its payoff is

$$
\theta_{g} b(Y)-C_{g},
$$

where $\theta_{g}>0$ is the valuation parameter of $g$. If $n$ contributes $C_{n}$, then its payoff is

$$
\theta_{n} b(Y)-C_{n}
$$

where $\theta_{n}>0$ is the valuation parameter of $n$.

7. See Hart [1995, p. 68] for a discussion on the distinction between investments in human capital as opposed to investments in physical capital in the context of the property rights approach to the theory of the firm. 
In the absence of any contracting problems, the parties will choose the level of investments to maximize joint surplus:

$$
\left(\theta_{n}+\theta_{g}\right) b(Y)-y_{g}-y_{n} .
$$

Let $y_{i}^{*}$ denote the joint surplus maximizing level of the investment by party $i$. It solves the following Lindahl-Samuelson type rule:

$$
\left(\theta_{g}+\theta_{n}\right) b_{k}\left(y_{g}^{*}, y_{n}^{*}\right)=1 \text { for } k \in\{1,2\},
$$

where $b_{k}(\cdot)$ is the derivative with respect to the $k$ th argument. Under our assumptions, $y_{g}^{*}>0, y_{n}^{*}>0$, and $\left(\theta_{g}+\theta_{n}\right) b\left(y_{g}^{*}, y_{n}^{*}\right)-$ $y_{g}^{*}-y_{n}^{*}>0$. Thus, it is optimal for the project to go ahead when both parties' valuations are taken into account and the joint surplus maximizing investments are implemented.

If there are no limits on contracting between the parties, we would expect a partnership to achieve the joint surplus maximizing outcome described above. We now consider a more realistic model with contracting imperfections. We follow the burgeoning literature, reviewed in Hart [1995], in supposing that the contract reached between the two parties is incomplete. Specifically, the investments in the project cannot be specified ex ante. This seems natural in our context-investments in the context of schools, credit programs, environmental protection, and preventive health care, etc. are extremely complex. ${ }^{8}$ Similarly, the realized benefits of such investments ("better quality") are hard to contract on.

As a consequence, each party will possess some bargaining power after the investments have been sunk, even if at the beginning of the game each party could choose from many partners. We use Nash bargaining so that the parties are assumed to split their renegotiation surplus 50/50 over the disagreement point. The anticipation of ex post bargaining over the surplus affects ex ante investment incentives, and since each party receives only a fraction of the social return from their investment, the resulting investments will differ from the case where each party could offer an up-front investment contingent transfer that would "price" the marginal benefit that the other generates. Moreover, the higher is the disagreement payoff of a party rela-

8. Indeed the inherent difficulty of monitoring performance in these activities is believed to be the main source of government failure as well as the nonviability of contracting them out to private firms [World Development Report 1997, p. 25]. 
tive to the other party, the stronger is her position in the bargaining game. To the extent that the disagreement payoffs depend on who is the owner of the project, and are sensitive to the investments, the ownership structure affects joint surplus. Our goal in this section is to characterize under whose ownership of the project (second-best) joint surplus is the highest.

We identify the project with all of its nonhuman assets which is akin to the notion of the firm in the property rights approach [Hart 1995]. These nonhuman assets might include equipment, inventories, buildings or locations, cash, patents and copyrights, a plan or a methodology, reputation or name, and the rights and obligations embodied in outstanding contracts. We assume that the owner of the project has residual control rights. This is a source of bargaining power. In particular, in the event of a dispute the owner has the authority to exclude anybody from working on the project at any stage.

The public good nature of the project implies that, if the parties disagree (which does not happen on the equilibrium path), then both parties may be better off ex post by transferring ownership from the original owner to the other party. ${ }^{9}$ Such "renegotiation" with costless transfers of ownership would make the initial assignment of property rights irrelevant. ${ }^{10}$ Hence, we assume that ex ante ownership does provide some form of credible commitment to maintain the ownership structure ex post. Since the parties will choose the joint surplus maximizing ownership structure, it is in everyone's interest to make such ownership commitments. One way to make such commitments would be if the first stage of the game had a "design" phase in which the owner undertakes certain actions (which are distinct from the investments) which require the owner's continued presence until the completion of the project. ${ }^{11}$

9. This issue does not arise in a private good context since, if the parties disagree, then the owner is strictly better off by retaining ownership, even if this involves selling the assets for their scrap value.

10. This is easily seen in the example from the introduction. If the NGO is the owner, then she receives 3 . However, if she handed over ownership ex post to the government, she would gain 5. Anticipating this, the government would not wish to invest in high quality whether the government or NGO was the owner as it would always receive a payoff of 1 .

11. One possible reason is that these decisions, like the investments themselves, are qualitative and relationship-specific in nature. This makes ownership difficult to transfer at a later stage. An alternative reason why it may be costly to transfer ownership ex post is that the owner enters into formal or implicit contractual relationships with third parties (e.g., banks, suppliers, staff) in relation to the project and it may be costly to transfer these obligations to another 
The game has the following stages:

- Stage $1 . g$ and $n$ decide who should own the project, i.e., have residual rights of control over the assets created. The owner undertakes the design of the project.

- Stage 2. If a partnership is formed, then $g$ chooses $y_{g}$, and $n$ chooses $y_{n}$ which are henceforth sunk and cannot be changed.

- Stage 3. $g$ and $n$ bargain over whether to continue with the project with transfers being possible at this stage.

Ownership matters because it defines different status quo payoffs in the bargaining game. We assume that if the owner takes over the project completely in the event of bargaining breaking down, then each party enjoys a reduced level of surplus from the project. Let $B^{i}\left(y_{g}, y_{n}\right)$ denote the benefit from the project if bargaining breaks down when $i$ is the owner, where $i \in\{g, n\}$ with $B^{i}\left(y_{g}, y_{n}\right) \leq b\left(y_{g}, y_{n}\right)$. These functions are also assumed to be increasing and concave with $\partial^{2} B^{i}\left(y_{g}, y_{n}\right) / \partial y_{g} y_{n} \geq 0$ and $B^{i}(0,0)>0$ for $i=g, n$. For simplicity, we also assume that neither party can carry away some part of the results of her investment out of the project and put it to an alternative use in the event of disagreement. A key assumption is

Assumption 1. The marginal investment returns under different ownership structures satisfy

$$
\begin{aligned}
& b_{1}\left(y_{g}, y_{n}\right) \geq B_{1}^{g}\left(y_{g}, y_{n}\right)>B_{1}^{n}\left(y_{g}, y_{n}\right) \text { for all } y_{n} \\
& b_{2}\left(y_{g}, y_{n}\right) \geq B_{2}^{n}\left(y_{g}, y_{n}\right)>B_{2}^{g}\left(y_{g}, y_{n}\right) \text { for all } y_{g} .
\end{aligned}
$$

This says that the marginal return to a given type of investment is highest in the event of disagreement when the party that made the investment is the owner. Following Hart, Shleifer, and Vishny [1997], this assumption could be interpreted as saying that a part of the return of the investment of a player is embodied in her human capital and cannot be realized if she is fired.

party at a later stage. Indeed, if transfer of ownership (and hence contractual obligations) is anticipated at a later stage, the initial owner might have an incentive to spend more resources on the project account (e.g., borrowing) than needed if the relevant actions are subject to problems of asymmetric information. For example, a moral hazard based story would be, if the owner anticipates transferring ownership at a later stage, she will undertake less effort to cut costs. The new owner would not know until the very end after all uncertainties are resolved the net worth of the project that was transferred to her. 
The model is solved backwards. The ownership structure is important in defining the default payoffs in the stage 3 bargaining game. Let $\bar{u}_{g}^{i}(Y)$ and $\bar{u}_{n}^{i}(Y)$ denote the default payoffs of $g$ and $n$ when $i(=g, n)$ is the owner. Ownership of the project determines who chooses whether to go ahead with the project in the event that bargaining breaks down. After the investments have been made, if the two parties are able to reach an agreement, then $\left(\theta_{n}+\theta_{g}\right) b(Y)$ is ex post joint surplus.

Let $t$ denote the amount of ex post transfer from $n$ to $g$ which can be positive or negative. Then the equilibrium level of transfers when $i$ is the owner, using the Nash bargaining solution, is

$$
\begin{aligned}
& t=\arg \max _{z}\left\{\theta_{n} b(Y)-z-\bar{u}_{n}^{i}(Y)\right\}\left\{\theta_{g} b(Y)+z-\bar{u}_{g}^{i}(Y)\right\} \\
& =\frac{\left(\theta_{n}-\theta_{g}\right) b(Y)+\bar{u}_{g}^{i}(Y)-\bar{u}_{n}^{i}(Y)}{2} .
\end{aligned}
$$

The net of transfer ex post payoffs of $g$ and $n$ are therefore

$$
\begin{aligned}
& \frac{\left(\theta_{g}+\theta_{n}\right) b(Y)+\bar{u}_{g}^{i}(Y)-\bar{u}_{n}^{i}(Y)}{2} \\
& \frac{\left(\theta_{g}+\theta_{n}\right) b(Y)+\bar{u}_{n}^{i}(Y)-\bar{u}_{g}^{i}(Y)}{2} .
\end{aligned}
$$

We now contrast ownership by $g$ and $n$. When $i$ is the owner $(i=$ $g, n)$, the default payoffs are

$$
\begin{aligned}
& \bar{u}_{g}^{i}(Y)=\theta_{g} B^{i}\left(y_{g}, y_{n}\right) \\
& \bar{u}_{n}^{i}(Y)=\theta_{n} B^{i}\left(y_{g}, y_{n}\right) .
\end{aligned}
$$

Substituting these into the payoffs of each party, we find that when $i$ is the owner, the payoff of $g$ is

$$
v_{g}^{i}\left(y_{g}, y_{n}\right)=\frac{\left(\theta_{n}+\theta_{g}\right) b\left(y_{g}, y_{n}\right)+\left(\theta_{g}-\theta_{n}\right) B^{i}\left(y_{g}, y_{n}\right)}{2}-y_{g},
$$

while that of $n$ is

$$
v_{n}^{i}\left(y_{g}, y_{n}\right)=\frac{\left(\theta_{n}+\theta_{g}\right) b\left(y_{g}, y_{n}\right)+\left(\theta_{n}-\theta_{g}\right) B^{i}\left(y_{g}, y_{n}\right)}{2}-y_{n}
$$

The two players maximize the above payoffs with respect to their own investment levels, taking the investment of the other party as 
given. We focus on the resulting investments that constitute a Nash equilibrium. Our assumptions guarantee that the best response functions are well behaved and that an interior equilibrium in pure strategies exists. The proof of Proposition 1 of Hart and Moore [1990] can then be adapted quite easily to show that the Nash equilibrium investment levels are unique for any given type of ownership. We now have ${ }^{12}$

Proposition 1. Suppose that Assumption 1 holds. Then, at any Nash equilibrium, investment levels are below their joint surplus maximizing levels. Giving ownership to the party with the highest valuation improves investment incentives for both parties and results in the highest possible level of joint surplus.

This contrasts with the standard view about ownership of private firms, where ownership improves investment incentives of the owner, and decreases the investment incentive of the other parties. A direct implication of the above result is

Corollary. Even if the investment of one party is more important for the project than that of the other party, so long as she has a lower valuation she is not optimally the owner. In the limit if there is only one investing party, she is not optimally the owner if the valuation of the other party is higher.

In other words, the relative valuation of the project by the parties determines who should be the owner, rather than aspects of the technology. If the parties have the same valuation, then both forms of ownership are equivalent in terms of joint surplus. In contrast, the standard results of the property rights literature suggest that ownership is determined by the relative importance of the investments. In particular, if there is a single asset and one investor, then the investor should be the owner [Hart 1995, p. 45].

The key observation behind Proposition 1 is that giving the ownership to the more caring party raises the marginal return to investing of both parties. From (1) and (2) above, we see that ownership affects investment only from the second term in the payoffs: $\left(\theta_{g}-\theta_{n}\right) B^{i}\left(y_{g}, y_{n}\right)$ for the government and $\left(\theta_{n}-\right.$ $\left.\theta_{g}\right) B^{i}\left(y_{g}, y_{n}\right)$ for the NGO. If $\theta_{g}>\theta_{n}$, then investment incentives are higher for both when $g$-ownership raises the marginal return of $y_{g}$ and lowers the marginal return of $y_{n}$ in the event of dis-

12. The proofs of this and all subsequent results appear in the Appendix. 
agreement. But under Assumption 1, this is precisely what happens under $g$-ownership. The opposite holds true for $\theta_{g}<\theta_{n}$ where $n$-ownership is optimal.

The public goods nature of the project is key to understanding this-each party receives a payoff from the project's completion even if she is not directly involved with it. This implies that the party who cares more about the project, say $n$ (i.e., $\theta_{n}>\theta_{g}$ ), has a greater disagreement payoff whether or not she continues to be involved with the project. The more caring party is therefore able to get more than an equal split of the surplus irrespective of who is the owner. ${ }^{13}$ This bargaining advantage translates into higher investment incentives under Assumption 1.

While the above result is similar in spirit to the existing literature on property rights, the flip side of it is not: the investment of the party with the lower valuation is lower when she is the owner. Ownership does increase the marginal return from her investment in the project in the event of disagreement, as in the GHM framework. But there the owner is able to appropriate this marginal return to the full extent, which enhances her disagreement payoff relative to the other party, and hence her overall investment incentives. In our model, in contrast, even when she is fired from the project, the high valuation party benefits more from the investment of the owner, i.e., the low valuation party) This increases her bargaining strength relative to the owner, depressing the latter's investment incentives more than what is implied by simply splitting the ex post surplus equally. When the low valuation party is not the owner, the surplus due to her investment is lower if she is not involved with the project. The bargaining advantage of the high valuation party stems from her benefiting more from the other party's investment in the event of disagreement. If the surplus due to the low valuation party's investment is small when the parties disagree, the bargaining advantage of the high valuation party is less, which enhances the investment incentives of the low valuation party.

Finally, since both investments are higher when the party with the higher valuation is made the owner, given the (weak) complementarity of the investments of the two parties, the (second-best) joint surplus is higher.

13. However, note that the more caring party always makes a net transfer to the less caring party. For example, the payoff of $g$ when $i$ is the owner can be written as $\theta_{g} b\left(y_{g}, y_{n}\right)+\left[\left(\theta_{n}-\theta_{g}\right)\left\{b\left(y_{g}, y_{n}\right)-B^{i}\left(y_{g}, y_{n}\right)\right\}\right] / 2-y_{g}$. Since $b\left(y_{g}, y_{n}\right) \geq B^{i}\left(y_{g}, y_{n}\right)$, if $\theta_{n}>\theta_{g}$, g gets a net transfer from $n$. 
It is useful to compare our result with other recent papers which show that ownership does not necessarily improve investment incentives in the GHM setting, i.e., regarding the ownership of private firms. One set of papers, such as Chiu [1998], De Meza and Lockwood [1998], and Segal and Whinston [1998], consider the implications of "outside option bargaining." Under this, the above bargaining protocol is valid only if both parties receive more than their disagreement payoffs. Otherwise, if one party's outside option is binding, then she receives her disagreement payoff while the other party receives the remaining surplus. Ownership improves a party's outside option in the GHM setup. Suppose that when a party is made the owner, the outside option constraint starts to bind. Now the other party's investment incentives would go up since she receives the full marginal returns from her investment. Rajan and Zingales [1998] propose another possible exception to the GHM result. If ownership induces greater specialized investment, it may also depress a party's outside option (since she is too specialized) and hence her bargaining power. This may decrease her incentive to invest. In contrast, if she is not the owner, she would not be concerned about the loss of outside opportunities because her alternatives would not be affected by her investment. Therefore, lack of ownership may increase investment incentives.

To conclude the discussion of the main results of the model, we briefly discuss its welfare implications. Whether the (secondbest) joint surplus maximizing arrangement chosen by the government and NGO under incomplete contracting will be good for social welfare is not clearcut. One important issue is whether the government is likely to be maximizing social welfare in the first place. It is well-known that the median voter's preference for public goods need not maximize social welfare (see, for example, Bergstrom [1979]). To the extent that welfare is not maximized by the government, it is unclear whether NGO involvement moves public good provision toward the social welfare maximizing outcome. The case for NGO raising social welfare will be most compelling when there are reasons to suppose that the government undervalues the benefits of the public good compared with social welfare. This is consistent with the arguments often advanced to justify the role of NGOs in developing countries. These are the apathy or inefficiency of most governments, or the presence of "neglected" groups in the population who are not represented in the political calculus. On the other hand, if the government's 
objective function is not too different from the social welfare function, involvement of "overzealous" NGOs may reduce welfare by inducing overprovision, as is sometimes alleged by critics of NGOs who view them as lobbies for some particular causes.

\section{Extensions}

In this section we discuss the robustness of Proposition 1 to some alternative specifications. First, we consider the role of joint ownership. Second, we introduce the possibility that one party does not care about the project directly. Third, we study the implications of allowing the benefit from the investments to have a public as well as private good component where the latter can be appropriated by the owner in the event of disagreement. Fourth, we consider what would happen in the case where the investments are perfect substitutes. Finally, we examine the role of "ideology," namely, allowing the possibility that while the two parties may care about the project (e.g., good schools), they might have very different views of how to design it (religious versus secular).

We develop the extensions in a slightly simpler framework where the payoffs are additive. Let $b(Y)=a_{g} \mu\left(y_{g}\right)+a_{n} \mu\left(y_{n}\right)$, $B^{n}\left(y_{g}, y_{n}\right)=\lambda_{g} a_{g} \mu\left(y_{g}\right)+a_{n} \mu\left(y_{n}\right)$ and $B^{g}\left(y_{g}, y_{n}\right)=a_{g} \mu\left(y_{g}\right)+$ $\lambda_{n} a_{n} \mu\left(y_{n}\right)$, where $\mu(\cdot)$ is a well-behaved increasing, concave function satisfying the Inada endpoint conditions, with $\mu(0)>0$. The parameters $a_{g}$ and $a_{n}$ capture the importance of the investments, and $\lambda_{g}$ and $\lambda_{n}$ are positive fractions that denote what proportions of the returns of the investments accrue to the project if the other party operates it alone. As in Hart, Shleifer, and Vishny [1997], the parameter $1-\lambda_{i}$ is the part of the return to investment of $i$ that is embodied in her human capital and cannot be realized if she is fired. This guarantees that Assumption 1 holds. Let $f(\gamma) \equiv$ arg $\max _{z \geq 0}\{\gamma \mu(z)-z\}$. It is easily checked that under our assumptions, $f(\cdot)$ is an increasing function. Using this notation, it is easy to check that the investment levels under $g$-ownership are $y_{g}=f\left(\theta_{g} a_{g}\right)$ and $y_{n}=f\left(\left(\theta_{g}\left(\left(1-\lambda_{n}\right) / 2\right)+\theta_{n}\left(\left(1+\lambda_{n}\right) / 2\right)\right) a_{n}\right)$, while those under $n$-ownership are $y_{g}=f\left(\left(\theta_{g}\left(\left(1+\lambda_{g}\right) / 2\right)+\right.\right.$ $\left.\left.\theta_{n}\left(\left(1-\lambda_{g}\right) / 2\right)\right) a_{g}\right)$ and $y_{n}=f\left(\theta_{n} a_{n}\right)$.

\section{III.1. Joint Ownership}

So far, we considered only the possibility that projects were owned by a single party. Suppose, instead that ownership is joint, 
in the sense that the project cannot go ahead if the parties fail to agree; i.e., $B^{g}\left(y_{n}, y_{g}\right)=B^{n}\left(y_{n}, y_{g}\right)=0$ for all $\left(y_{n}, y_{g}\right) .{ }^{14}$ This implies that the disagreement payoffs are zero for both parties, and as a result, the payoffs will be

$$
\begin{aligned}
& v_{g}^{j}\left(y_{g}, y_{n}\right)=\frac{\left(\theta_{n}+\theta_{g}\right)\left\{b\left(y_{n}, y_{g}\right)\right\}}{2}-y_{g}, \\
& v_{n}^{j}\left(y_{g}, y_{n}\right)=\frac{\left(\theta_{n}+\theta_{g}\right)\left\{b\left(y_{n}, y_{g}\right)\right\}}{2}-y_{n} .
\end{aligned}
$$

Comparing these payoffs of $g$ and $n$ with those given in Section II, it is clear that the investment incentives of the more caring party will be lower and that of the less caring party will be higher under joint ownership compared with individual ownership by $g$ or $n$. A direct implication of this is

Proposition 2. Suppose that Assumption 1 holds. The investment incentive of the more caring party will be lower and that of the less caring party will be higher under joint ownership compared with the two pure forms of ownership. If the investment of the less caring party is relatively more important, joint ownership may yield a higher level of joint surplus compared with ownership by the more caring party.

Figure I illustrates this result for an example. ${ }^{15}$ It plots the difference in valuations, $\theta_{n}-\theta_{g}$, against the difference in investment productivities, $a_{n}-a_{g}$, to illustrate the regions in which the different ownership structures will be chosen. From Proposition 1 we know that if we restrict our attention to ownership by $g$ and $n$ only,

14. It is possible that $B^{i}=0$ due to the technology of the project, for example, when the presence of $j$ is essential for the project to yield any surplus, in which case ownership by $i$ and joint ownership would be equivalent. The conclusion is the same as this case, as long as $\theta_{i}<\theta_{j}$. If $\theta_{i}>\theta_{j}$, then it is easy to check that $i$ 's incentives are better when $j$ is the owner, while $j$ 's incentives are better when $i$ is the owner.

15. This assumes that $\mu\left(y_{i}\right)=2 \sqrt{a_{i} y_{i}}+A, i=g, n$, where $A$ is a positive constant. We hold $\theta_{g}+\theta_{n}$ and $a_{n}+a_{g}$ constant at $\bar{\theta}$ and $\bar{a}$, and restrict the comparison to cases where $\left|\theta_{g}-\theta_{n}\right|^{g} \leq \bar{\theta}$ and $\left|a_{n}-a_{g}\right| \leq \bar{a}$. It is easy to check that for $\theta_{n}-\theta_{g}>0$, joint ownership dominates $n$-ownership if and only if

$$
a_{g}-a_{n}>\bar{a} \frac{2\left(1-\lambda_{g}\right) \bar{\theta}-\left(1+\lambda_{g}^{2}\right)\left(\theta_{n}-\theta_{g}\right)}{2\left(1+\lambda_{g}\right) \bar{\theta}-\left(1-\lambda_{g}^{2}\right)\left(\theta_{n}-\theta_{g}\right)},
$$

where the right-hand side is a decreasing and concave function of $\left(\theta_{n}-\theta_{g}\right)$. We also assume that $\lambda_{g}$ is small enough so that $\lambda_{g}\left(2+\lambda_{g}\right)<1$ (which is the case for $\left.\lambda_{g} \leq 1 / 3\right)$. The latter implies that $a_{g}-a_{n}$ always has to exceed some minimum threshold for joint ownership to dominate. 


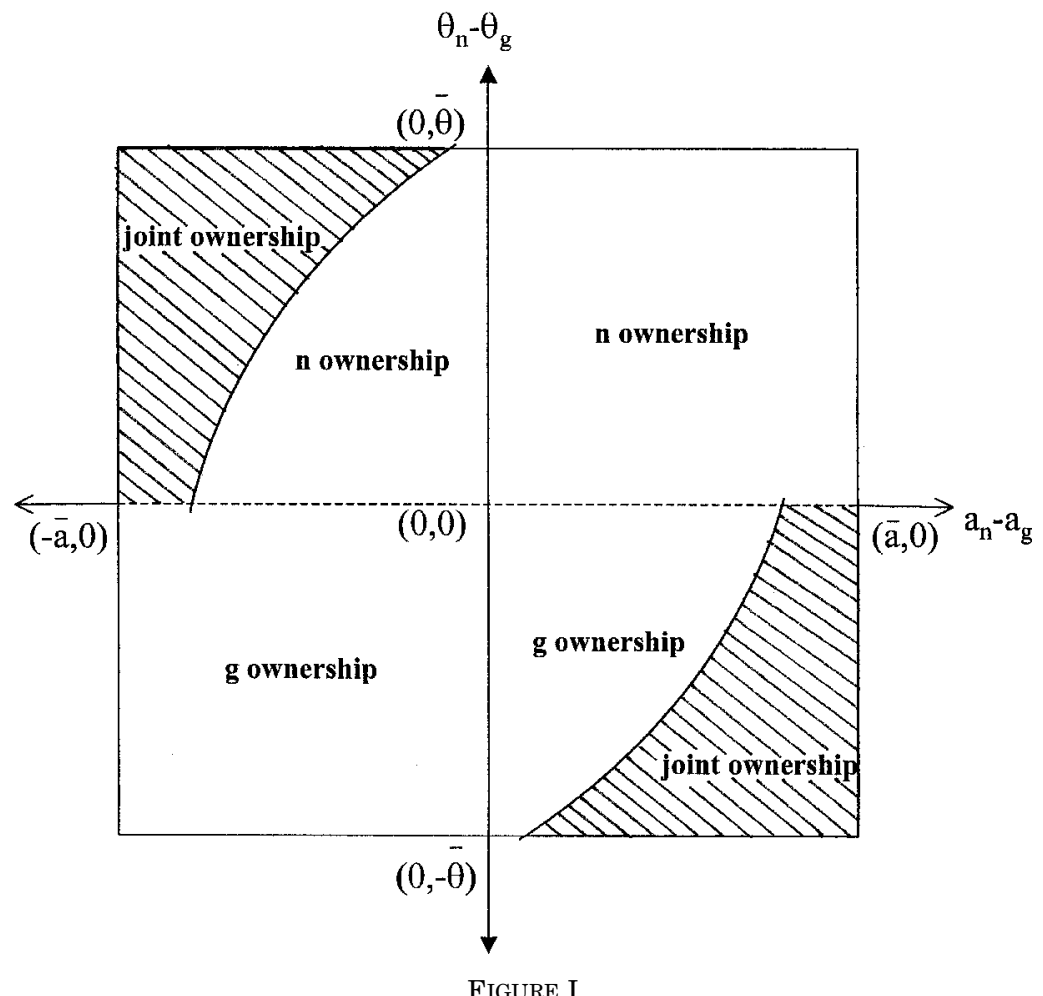

then the area above the horizontal axis would depict the set of parameter values for which ownership by $n$ dominates ownership by $g$, and the area below the horizontal axis, the opposite. However, if we allow for joint ownership, even if $\theta_{n}-\theta_{g}>0$, if $a_{g}$ is sufficiently higher than $a_{n}$, joint ownership would dominate ownership by $n$, and conversely, when $\theta_{g}-\theta_{n}>0$. In the figure the shaded areas depict parameter values for which joint ownership is optimal. Notice that, for $\theta_{n}=\theta_{g}$, all three forms of ownership yield the same (secondbest) level of joint surplus.

To see the intuition behind this result, consider the case where there is only one investor, say g. In the GHM setup, $g$ should own the asset. In our setup, as we explained above, if $n$ values the project more she would be able to get more than half of the joint surplus irrespective of who is the owner. When $n$ is the owner, the realized benefit from $g$ 's investment in the state of disagreement is less by 
Assumption 1, and so n's bargaining advantage is less. This implies that $n$ should be the owner. But with joint ownership, $n$ has no bargaining advantage at all, which is even better from the point of $g$ 's investment incentives. In the general case, $n$ 's own investment incentives will be worst under joint ownership, and so the optimal choice of ownership will depend on the relative importance of the two types of investments.

\section{III.2. Contracting with a for-Profit Firm}

We now consider what happens when one investing party gets no intrinsic value from the project and completing the project is costly. This will help to understand where the public good nature of the project is important. Hence, we consider this case, where $\theta_{n}=0$ and $\theta_{g}>0$. Costly project completion is captured by there being a small positive cost, $c>0$, of completing the project after the investments are made which we assume is paid by the owner. ${ }^{16}$ This will imply a key difference with the baseline model as the for-profit NGO will not wish to complete the project if it is the owner and there is disagreement. In this case, if $g$ is the owner, the payoffs of the two parties are ${ }^{17}$

$$
\begin{aligned}
& v_{g}^{g}\left(y_{g}, y_{n}\right)=\frac{\theta_{g}\left\{b\left(y_{g}, y_{n}\right)+B^{g}\left(y_{g}, y_{n}\right)\right\}-c}{2}-y_{g} \\
& v_{n}^{g}\left(y_{g}, y_{n}\right)=\frac{\theta_{g}\left\{b\left(y_{g}, y_{n}\right)-B^{g}\left(y_{g}, y_{n}\right)\right\}-c}{2}-y_{n},
\end{aligned}
$$

while under $n$-ownership the payoffs are

$$
\begin{aligned}
& v_{g}^{n}\left(y_{g}, y_{n}\right)=\frac{\theta_{g} b\left(y_{g}, y_{n}\right)-c}{2}-y_{g} \\
& v_{n}^{n}\left(y_{g}, y_{n}\right)=\frac{\theta_{g} b\left(y_{g}, y_{n}\right)-c}{2}-y_{n} .
\end{aligned}
$$

Clearly, the investment incentive of $n$ is now higher under $n$ ownership, while that of $g$ is higher under $g$-ownership, which

16. We assume that the continuation cost is small enough so that $\theta_{g} B^{g}(0,0)>c$.

17. This uses the fact that

$$
t=\frac{\left(\theta_{n}-\theta_{g}\right) b(Y)+\delta c-(1-\delta) c+\bar{u}_{g}^{i}(Y)-\bar{u}_{n}^{i}(Y)}{2},
$$

where $\delta=1$ if $g$ is the owner and $\delta=0$ if $n$ is the owner. 
brings out the familiar costs and benefits of ownership in the GHM framework. Observe also that, in this case, $n$-ownership is formally equivalent to joint ownership. Then extending the logic of Proposition 2, we have

Proposition 3. Suppose that one party does not value the project and would not complete it in the event of disagreement if she was the owner, but Assumption 1 continues to hold. Then, this party will optimally be the owner if her investment is sufficiently more important. Otherwise, the higher valuation party will optimally be the owner.

In Figure I, if we set $\theta_{n}=0$ and focus our attention only on the area below the horizontal axis, the shaded area in the fourth quadrant would depict parameter values for which ownership by a for-profit firm would dominate ownership by $g$.

Thus, our model underlines that private ownership arrangements with for-profit contractors must come from their intrinsic technological expertise. Otherwise, government ownership is desirable. $^{18}$

\section{III.3. Investment Outcomes Have a Private Good Component}

Our basic case was of a pure public good. We now suppose that there is also a private good component associated with the project. For example, both $g$ and $n$ could invest to devise ways of cutting costs of running a school, but this could adversely affect school quality. Between the two parties, the gains from cutting costs is a private good, while the quality of the school is a public good. This analysis is in the spirit of Hart, Shleifer, and Vishny [1997]. ${ }^{19}$

For simplicity, let there be a single investor, say $n$ (i.e., $a_{g}=$ 0 ). It is straightforward to allow both parties to invest, and we will remark on what happens in this case at the end of this section. Now $y_{n}$ generates a public good component $a_{n} \mu\left(y_{n}\right)$ as before, but it also has a private good component, $\beta\left(y_{n}\right){ }^{20}$ Let $\alpha$

18. A good example of private ownership in this case is the Private Finance Initiative in the United Kingdom whereby ownership of public hospitals and other facilities is being transferred on the grounds that the private sector has better access to the capital market.

19. This is basically a simplified version of their model with the main difference being that both parties care about the quality of the project.

20. In the Hart-Shleifer-Vishny [1997] model, investment leads to a reduction in cost, but also affects quality of the service negatively. Our model is directly comparable to theirs if $\mu(\cdot)$ is a decreasing function of $y_{n}$. 
and $(1-\alpha)$ denote the relative importance of the public and private good components of these investments in joint surplus. As above, if $n$ is fired, only a fraction $\lambda_{n}$ of the total benefits of her investments (i.e., the sum of the private and public good components) are available. We show that

Proposition 4. Suppose that Assumption 1 holds. Then, if the investments generate a private and a public good component, optimal ownership depends on the relative importance of the two components. If the public good component is sufficiently important, the high valuation party should be the owner even if she is not the investor. Otherwise, the investor should be the owner.

As far as the public good component is concerned, Proposition 1 implies that the higher valuation party should be the owner. On the other hand, for the private good component, the investor should be the owner, as we would expect from the GHM approach. Naturally, if $\theta_{n}>\theta_{g}$, these forces are working in the same direction, and so $n$ should be the owner. If $\theta_{g}>\theta_{n}$, optimal ownership depends on the relative importance of the public and private good components, i.e., the value of $\alpha^{21}$ If we allow both parties to invest, then the conclusion is the same-if the public good component is important, then the high valuation party should be owner. If the private good component is important, $g$-ownership will lead to a higher value of $y_{g}$ but a lower value of $y_{n}$, and the opposite for $n$-ownership. This trade-off will be resolved depending on the relative importance of the private good components of these two investments, as in GHM.

\section{III.4. Perfect Substitutes}

The most standard model of public and private provision where the private sector can "crowd-out" public provision takes a technology where the investments of $g$ and $n$ are perfect substitutes. We now consider what happens in this case. Assume that

21. In terms of the Hart-Shleifer-Vishny [1997] model, if $\theta_{n}=0$, then $y_{n}$ would be too high under private ownership while it would be too low under public ownership compared with the joint surplus maximizing level. However, if $\theta_{n}>0$ while this proposition is still valid, $y_{n}$ under $n$-ownership would move closer to the joint surplus maximizing level (i.e., it is lower than when $\theta_{n}=0$ ), while $y_{n}$ under g-ownership would move farther away from the joint surplus maximizing level (i.e., it is lower than when $\theta_{n}=0$ ). As a result, allowing contracting with nonprofits relaxes the cost-quality trade-off involved with privatization and (weakly) strengthens the case against government ownership. 
$b\left(y_{g}, y_{n}\right)=\eta\left(y_{g}+y_{n}\right), B^{g}\left(y_{g}, y_{n}\right)=\eta\left(y_{g}+\lambda y_{n}\right)$ and $B^{n}\left(y_{g}, y_{n}\right)=\eta\left(\lambda y_{g}+y_{n}\right)$, where $\eta(\cdot)$ is a well-behaved increasing, concave function satisfying the Inada endpoint conditions and $\lambda \in(0,1)$. Under full contracting, the parties simply determine the total first-best investment level with the precise distribution of total investment between $y_{g}$ and $y_{n}$ being irrelevant for joint surplus. For the second-best allocation, we show that

Proposition 5. Suppose that the investments of the two parties are perfect substitutes and that Assumption 1 holds. Then, there is only one investor in equilibrium, and this party should also be the owner. The owner-investor should be the party that values the project most highly.

The intuition is simple and follows from the fact that the two investments are perfect substitutes. The more caring party will always have a bargaining advantage for reasons described in the previous section. This will translate into a higher marginal return from her investment compared with that of the other party. Since these investments are perfect substitutes, only the high valuation party will invest in equilibrium under both types of ownership. Since we assume that if a party is the owner, the marginal return from her investment in the project is higherthis immediately implies that the high valuation party should also be the owner. While it is still true that the party with the highest valuation should own the project, there is no separation between the owner and the investor in this case.

\section{III.5. Ideology}

We now study the effect of introducing another noncontractible input that determines the payoffs of the two parties from the public good that we call "ideology." We assume that the owner of the project can choose this input after the investments are sunk. While both parties value the project, they may have different views on designing the project. This might, for example, reflect the weights that each party attaches to particular beneficiary groups (e.g., men versus women, some particular ethnic group), a view about the environmental impact of a project, the religious content of an educational program, or the role of family planning in a health program. Such issues are frequently encountered in situations where NGOs function in practice.

To model this, let $r \in\{0,1\}$ represent ideology-we assume that $g$ prefers $r=0$ and $n$ prefers $r=1$. We suppose that 
ideology is chosen by the owner and is costless. It is also valuesubtracting so that designing the project to suit one party diminishes the payoff of the other party and lowers the joint payoff from the project. Specifically, the valuation of $g$ is now $\{q r+(1-r)\} \theta_{g}$ instead of $\theta_{g}$, and that of $n$ is $\{q(1-r)+r\} \theta_{n}$ instead of $\theta_{n}$. The parameter $q \in(0,1)$ captures the degree of homogeneity in tastes between $g$ and $n .^{22}$ Thus, $q$ might represent the fraction of beneficiaries $n$ cares about when $g$ runs the project and vice versa. Alternatively, $g$ may value the fraction of time that $n$ devotes to teaching mathematics in a school $(q)$, but may receive zero value from the fraction of teaching time $(1-q)$ devoted to a particular religion or ideology. ${ }^{23}$ Since the owner chooses $r$, her investment incentives are unaffected, but the incentive of the other party is lower. If this loss is large enough, it is now possible that Proposition 1 would not go through. We show

Proposition 6. Suppose that parties have different preferences regarding noncontractible aspects of project design ("ideology") that affect their valuation of the project and that Assumption 1 holds. If the owner chooses the project design, her investment incentive is higher while that of the other party is lower. If preference differences are large enough, joint surplus need no longer be higher when the high valuation party is the owner.

The incentive of the higher valuation party is stronger when she is the owner now, since she gets to choose project design. But it need no longer be the case that the incentive of the lower valuation party is stronger when the high valuation party is the owner. In other words, the main effect of introducing value-subtracting ideology is that it reduces the public goods aspect of the project which drives our main results. However, we must distinguish this case from the one where one party does not care about the project at all (as in subsection III.2). Even in the case of extreme preference differences $(q=0)$ the lower valuation party cares about the

22. The parameter $q$ is similar to what Aghion and Tirole [1994] refer to as congruence of objectives.

23. In a recent paper Kremer and Sarychev [1998] argue that education is publicly provided rather than publicly funded, even when there is evidence showing that private schools are more efficient, because people have preferences over noncontractible aspects of the education of other people's children. They argue that the most important of these noncontractible aspects of education is likely to be ideology. For example, it is possible to require schools to teach evolution or the history of the Civil War, but it is hard to verify in what light these things are taught to students. 
project when she is the owner and will complete it in the event of disagreement.

\section{Applications}

\section{IV.1. NGOs in Developing Countries}

Our main application is to the involvement of NGOs in public good provision. These are nonprofit organizations that have been increasingly involved in the provision of relief and welfare, social services, and various development projects (e.g., agricultural extension, microlending) in less developed countries over the last two decades. ${ }^{24}$

From the point of view of our framework of two parties making complementary investments in a public good, of most interest is the growth of public-private partnerships in this context. ${ }^{25}$ Consistent with our focus on incomplete contracting, the literature on NGOs has many references to problems that arise due to the complex nature of the various inputs involved in public projects, and the fact that the chosen organizational forms of collaboration between governments and NGOs vary in response to these problems (see Malena [1995]). In addition, there is a lot of anecdotal evidence showing the importance of ownership and of holdup problems. Most NGOs feel that the most difficult aspect of working with governments is in dealing with bureaucratic processes, delays, and corruption. Often projects have to be canceled at the implementation stage due to disagreements between the government and the NGO (see Malena [1995] and Sen [1998]).

In their wide-ranging survey of government NGO-partnerships in agricultural extension, Farrington and Bebbington [1993] and Farrington and Lewis [1993] confirm the importance of partnerships in Latin America, Africa, and Asia. The government retains responsibility for $R \& D$ expenditures and provides

24. According to the Human Development Report [1993], there are more than 50,000 NGOs working at the grass-roots level in developing countries whose activities have affected the lives of 250 million individuals. While there are some very large international and national NGOs (e.g., Oxfam, BRAC) for the most part a typical NGO is " . . . a small agency with a handful of staff working in a cluster of villages in a particular locality" [Riddell and Robinson 1995].

25. According to the World Bank [1998], partnerships are to be distinguished from contractual relationships. The latter are project specific and are worked out in a fair bit of detail. In contrast, partnerships entail clear overall objectives, but not much details. The three main costs of partnerships are said to include "... dealing with conflicts, endless discussion, and exploitation." 
training and technical support to NGO staff, while NGOs are given the entire task of building an extension system to serve farmers owing to their greater familiarity with local conditions and superior ability to communicate with farmers. The genuinely collaborative nature of these arrangements is noted by Farrington and Bebbington [1993, p. 153]: "Careful planning of responsibilities (between NGOs and governments) is particularly important in fully collaborative efforts-such as joint on farm trials-in which a successful outcome requires carefully scheduled inputs from both sides." Other instances of public-private partnerships include the case of health care services and antipoverty programs. In Tanzania the government and churches collaborate to provide the services of a district hospital. The church manages the hospital and provides training to staff, while the government provides financial support and personnel [Mliga 1998]. In various states of India, the government provides resources and planning, while NGOs organize local groups and train them to make effective use of antipoverty programs [Farrington and Lewis 1993].

In general, the literature emphasizes that NGOs are more in tune with the interests of the poor than many governments. Thus, a UN report cites the fact that the rural poor are given higher priority by NGOs as one of the main advantages of NGO over government provision for social services and antipoverty programs even while recognizing that governments have a comparative advantage due to their much greater resource and broader institutional framework. ${ }^{26}$ This is a clear confirmation of our main result that a more caring party should be the owner of a public project irrespective of comparative advantage in the production of the service.

Our analysis presumes that both parties have a minimum valuation of the project. There is considerable support for this in the literature on public-private partnerships. According to Bratton [1989] and Clark [1995], successful government-NGO partnerships have emerged only when both parties have had some minimum commitment toward the beneficiaries. Wherever the government is not committed to poverty alleviation or is repressive, NGOs have preferred to chart their own course and stay away from any dealings with government. Conversely, demo-

26. United Nations Interagency Committee on Integrated Rural Development for Asia and the Pacific [1992, p. 20]. 
cratic countries where the government or even individual ministries have a positive social agenda, collaborations with NGOs have emerged as in India, Sri Lanka, and recently, in various Latin American countries. In contrast, many African governments have not been, in general, either democratic or responsive to the poor, and as a result (mostly church-based) NGOs have conducted relief and welfare work, as well as provide health and education services entirely on their own.

Our model emphasizes the importance of the parties' project valuations as a major determinant of organizational form rather than the importance of inputs unless cost-saving issues are important (subsection III.3). According to the World Development Report [1997, p. 25], governments that delegate some functions to private organizations, typically prefer NGOs for delivery of social services. The report argues that this is not necessarily because NGOs are more cost-efficient but because they are perceived to be committed to high quality or serve better some groups due to their religious or ideological orientation (which is a proxy for project valuation). In contrast, for services such as the management of infrastructure, for-profit contractors are preferred because cost efficiency is the major concern (e.g., road maintenance in Brazil, water supply in Guinea, and ports in Malaysia). This is consistent with our model: for activities where performance is hard to monitor, commitment to the beneficiaries (i.e., project valuation) is more important than production or cost efficiency considerations in determining who should be given the responsibility of provision.

Finally, our discussion of the role of ideology suggests that valuation need not be "neutral"-even if both the government and the NGO care about the beneficiaries, they may have very different views on how to help them. The greater is the divergence of these views, the less likely we are to see partnerships. Various case studies strongly confirm this prediction. According to Farrington and Lewis [1993], in the ideological spectrum from neutral to nonneutral activities, partnerships are more likely to form the more "neutral" the activity such as relief and welfare, and development (delivery of inputs and technology, adapting technology to local needs). In contrast, conflicts arise for NGOs engaged primarily in advocacy (e.g., land reform, environmental protection, higher wages, legal rights, human rights). Conversely, governments run by ideologically driven politically parties, both on the left and the right, are less likely to collaborate with NGOs (see Sen's [1998] study of government-NGO collaborations in India). 


\section{IV.2. Other Applications}

The notion of joint provision of public goods by concerned parties is of much wider interest than government-NGO relations. There are many situations where public goods are produced by partners. Here, we mention a few possibilities.

Our framework can be applied to situations where there is significant presence of positive or negative externalities. For example, consider a situation where there are two adjacent localities (or two firms) on the side of a lake. Each party can undertake a noncontractible action that affects the quality of the water which in turn affects the payoff of both parties. Our framework suggests that independent of the technology that governs how the actions of these parties affect the quality of the lake water, the party who is most affected by it should own it or have jurisdiction over it. ${ }^{27}$

Our analysis goes through directly if we consider public goods about which different units of the government, say, local versus state or federal, care differentially. If we make the plausible assumption that the local government cares more about the local public good, then it should be the owner even if resources from the state or federal government are much more important for its operation. Compared with the usual argument based on superior local information, this can be interpreted as an alternative argument for decentralization.

A very different application of the model would be to some problems in the economics of the family where family members can be viewed as jointly producing household level public goods. For example, the economic analysis of divorce and child-support payments treats the well-being of a child as a household public good that enters the utility function of both parents whether they are married or divorced (see Weiss and Willis [1985]). Our framework can be applied to analyze the effect of child custody laws on investments in children. The principle suggested by the model here would be to assign the right to the child in the event of marriage breakup to the party who values the child's well-being the most. Our model predicts that this will lead to the best incentives for both parents provided that these investments are complements. ${ }^{28}$

Our model could also be applied to scientific or artistic joint

27. However, bargaining in this situation may be complicated by the fact that the valuation of the parties could be subject to asymmetric information (see Klibanoff and Morduch [1995]).

28. See Rasul [2000] for an empirical analysis for Malaysia based on the model developed here. 
ventures where parties directly care about the outcome of the project. $^{29}$ In this instance, the question is who should own the project or be the leader. The main prediction of our basic model is that this should be the party who cares most about the outcome rather than the party whose investment is more important.

Another application of the model is to contributions toward political campaigns by parties who have a common interest and complementary expertise. The main principle of our basic model suggests that the assets created in such projects should be owned by the party who cares most about the outcome-presumably the victory of a particular candidate or a cause. Again, this is not necessarily the party whose expertise is most crucial to the success of the campaign.

\section{Concluding Remarks}

This paper has set out a framework for thinking about the responsibilities of the state and the voluntary sector in providing inputs/finance to public projects. Under the reasonable assumption that contracts are incomplete and hence investments are subject to holdup, we have a theory of ownership of public goods. The model developed here delivers the presumption that ownership should reside with the party that cares most about the project. The main value of the framework developed here is to provide a basis for thinking systematically about how the private sector can be involved in the provision of public goods, a process that has proceeded apace in the real world without any underpinning model to understand it.

\section{ApPendix: Proofs of Propositions}

\section{Proof of Proposition 1}

Consider a vector $\left(y_{g}, y_{n}\right)$ of investment levels such that $\partial v_{g}^{i}\left(y_{g}, y_{n}\right) / \partial y_{g} \leq 0$ and $\partial v_{n}^{i}\left(y_{g}, y_{n}\right) / \partial y_{n} \leq 0$ with strict equality for at least one player so that either $y_{g}$ or $y_{n}$ is strictly positive. Then, we know from Hart and Moore [1990, Proposition 1] that

29. It is important to emphasize that the parties need to care directly about the project for our analysis to apply; i.e., they must benefit from the success of the project irrespective of whether they are directly involved with it until the very end, or receive any personal rewards (financial, reputational, etc.). This certainly excludes many commonly studied cases of partnerships or team production. 
any ownership structure that gives all agent's a higher marginal investment return will yield a higher vector of Nash equilibrium investments, and higher joint surplus. Differencing the marginal investment returns under the two possible ownership structures,

$$
\frac{\partial v_{g}^{g}\left(y_{g}, y_{n}\right)}{\partial y_{g}}-\frac{\partial v_{g}^{n}\left(y_{g}, y_{n}\right)}{\partial y_{g}}=\frac{\left(\theta_{g}-\theta_{n}\right)\left(B_{1}^{g}\left(y_{g}, y_{n}\right)-B_{1}^{n}\left(y_{g}, y_{n}\right)\right)}{2}
$$

and

$$
\frac{\partial v_{n}^{g}\left(y_{g}, y_{n}\right)}{\partial y_{n}}-\frac{\partial v_{n}^{n}\left(y_{g}, y_{n}\right)}{\partial y_{n}}=\frac{\left(\theta_{n}-\theta_{g}\right)\left(B_{2}^{g}\left(y_{g}, y_{n}\right)-B_{2}^{n}\left(y_{g}, y_{n}\right)\right)}{2}
$$

It follows immediately from Assumption 1 that $g$-ownership has highest marginal return for both investors if $\theta_{g}>\theta_{n}$ and $n$-ownership has the highest for both investors if $\theta_{g}<\theta_{n}$. Now observe that, given Assumption 1,

$$
\begin{aligned}
& \frac{\partial v_{g}^{i}\left(y_{g}, y_{n}\right)}{\partial y_{g}}=\frac{\left(\theta_{n}+\theta_{g}\right) b_{1}\left(y_{g}, y_{n}\right)+\left(\theta_{n}-\theta_{g}\right)}{2} B_{1}^{i}\left(y_{g}, y_{n}\right) \\
&<\left(\theta_{n}+\theta_{g}\right) b_{1}\left(y_{g}, y_{n}\right)
\end{aligned}
$$

and

$$
\begin{aligned}
& \frac{\partial v_{n}^{i}\left(y_{g}, y_{n}\right)}{\partial y_{n}}=\frac{\left(\theta_{n}+\theta_{g}\right) b_{2}\left(y_{g}, y_{n}\right)+\left(\theta_{g}-\theta_{n}\right) B_{2}^{i}\left(y_{g}, y_{n}\right)}{2} \\
&<\left(\theta_{n}+\theta_{g}\right) b_{2}\left(y_{g}, y_{n}\right) .
\end{aligned}
$$

Thus, at any Nash equilibrium, investment levels are below their joint surplus maximizing levels $\left(y_{g}^{*}, y_{n}^{*}\right)$. Hence, second-best joint surplus is highest when the ownership structure is chosen that gives the highest investment levels in any Nash equilibrium.

QED

\section{Proof of Proposition 2}

It is readily checked that the equilibrium investment levels under joint ownership are $y_{g}=f\left(\left(\left(\theta_{n}+\theta_{g}\right) / 2\right) a_{g}\right)$ and $y_{n}=$ $f\left(\left(\left(\theta_{n}+\theta_{g}\right) / 2\right) a_{n}\right)$. Now consider the case $\theta_{n}>\theta_{g}$. (The argument where $\theta_{g}>\theta_{n}$ is symmetric.) In this case, 


$$
f\left(\frac{\theta_{n}+\theta_{g}}{2} a_{g}\right)>f\left(\left(\theta_{g} \frac{1+\lambda_{g}}{2}+\theta_{n} \frac{1-\lambda_{g}}{2}\right) a_{g}\right)>f\left(\theta_{g} a_{g}\right) .
$$

So $y_{g}$ is always higher under joint ownership. Now consider $y_{n}$. Here, we have

$$
f\left(\theta_{n} a_{n}\right)>f\left(\left(\theta_{g} \frac{1-\lambda_{n}}{2}+\theta_{n} \frac{1+\lambda_{n}}{2}\right) a_{n}\right)>f\left(\frac{\theta_{g}+\theta_{n}}{2} a_{n}\right) .
$$

Now as $a_{n} \rightarrow 0, y_{n}$ goes to zero under all three ownership structures, and the comparisons of $y_{g}$ dominate. Hence, joint ownership dominates $n$-ownership in terms of joint surplus in this case.

QED

\section{Proof of Proposition 3}

It is readily checked that the equilibrium investment levels under $g$-ownership are $y_{g}^{g}=f\left(\theta_{g} a_{g}\right)$ and $y_{n}^{g}=f\left(\theta_{g}\left(\left(1-\lambda_{n}\right) / 2\right) a_{n}\right)$ while those under $n$-ownership are $y_{g}^{n}=f\left(\left(\theta_{g} / 2\right) a_{g}\right)$ and $y_{n}^{n}=$ $f\left(\left(\theta_{g} / 2\right) a_{n}\right)$. Clearly, $y_{n}^{n}>y_{n}^{g}$ while $y_{g}^{g}>y_{g}^{n}$. Holding $a_{g}$ constant, as $a_{n} \rightarrow 0$, g-ownership dominates, and conversely, holding $a_{n}$ constant, as $a_{g} \rightarrow 0, n$-ownership dominates.

QED

\section{Proof of Proposition 4}

If the investments were contractible, then the value of $y_{g}$ and $y_{n}$ chosen to maximize joint surplus would be given by

$$
\alpha\left(\theta_{g}+\theta_{n}\right) a_{n} \mu^{\prime}\left(y_{n}\right)+(1-\alpha) \beta^{\prime}\left(y_{n}\right)=1 .
$$

If $g$ is the owner, the disagreement payoffs of $g$ and $n$ are, respectively, $\lambda_{n}\left[\alpha \theta_{g} a_{n} \mu\left(y_{n}\right)+(1-\alpha) \beta\left(y_{n}\right)\right]$ and $\lambda_{n} \alpha \theta_{n} a_{n} \mu\left(y_{n}\right)$. Similarly, if $n$ is the owner, then the disagreement payoffs are $\alpha \theta_{g} a_{n} \mu\left(y_{n}\right)$ and $\alpha \theta_{n} a_{n} \mu\left(y_{n}\right)+(1-\alpha) \beta\left(y_{n}\right)$. Notice that only the owner appropriates the private good component. Hence the value of $y_{n}$ that will be chosen under $g$-ownership is given by

$$
\frac{1-\lambda_{n}}{2}(1-\alpha) \beta^{\prime}\left(y_{n}\right)+\left\{\frac{1-\lambda_{n}}{2} \theta_{g}+\frac{1+\lambda_{n}}{2} \theta_{n}\right\} \alpha a_{n} \mu^{\prime}\left(y_{n}\right)=1 \text {. }
$$

Under $n$-ownership it is

$$
(1-\alpha) \beta^{\prime}\left(y_{n}\right)+\theta_{n} \alpha a_{n} \mu^{\prime}\left(y_{n}\right)=1 \text {. }
$$

If $n$ is a for-profit firm $\left(\theta_{n}=0\right)$, it follows directly from these first-order conditions that compared with the joint surplus maxi- 
mizing level, $y_{n}$ would be lower under both types of ownership arrangements. Now suppose that $\theta_{n}>0$ and $\theta_{g}>0$. Then, if the public good component is ignored (i.e., $\alpha$ is very small), $y_{n}$ is higher under $n$-ownership. However, if $\alpha$ is large, then optimal ownership choice depends on the relative values of $\theta_{g}$ and $\theta_{n}$, as in Proposition 1. As a result, when $\theta_{n}>\theta_{g}, n$-ownership is optimal. If $\theta_{g} \geq \theta_{n}$, then $g$-ownership will yield higher surplus if $\alpha$ is high enough.

QED

\section{Proof of Proposition 5}

First, take the case $\theta_{g}>\theta_{n}$. We show that there will (generically) be a corner solution, and only the more caring party will invest under both types of ownership arrangements. Suppose, if possible, that an interior solution exists for both $y^{g}$ and $y^{n}$. Consider government ownership first. The first-order conditions for an interior solution are

$$
\begin{array}{r}
\theta_{g} \eta^{\prime}\left(y_{g}^{*}+y_{n}^{*}\right)=1 \\
\frac{\left(\theta_{n}+\theta_{g}\right)}{2} \eta^{\prime}\left(y_{g}^{*}+y_{n}^{*}\right)-\frac{\left(\theta_{g}-\theta_{n}\right)}{2} \lambda \eta^{\prime}\left(y_{g}^{*}+\lambda y_{n}^{*}\right)=1
\end{array}
$$

where $y_{g}^{*}>0$ and $y_{n}^{*}>0$. But

$$
\begin{aligned}
\frac{\left(\theta_{n}+\theta_{g}\right)}{2} \eta^{\prime}\left(y_{g}^{*}+\right. & \left.y_{n}^{*}\right)-\frac{\left(\theta_{g}-\theta_{n}\right)}{2} \lambda \eta^{\prime}\left(y_{g}^{*}+\lambda y_{n}^{*}\right) \\
& <\frac{\left(\theta_{n}+\theta_{g}\right)}{2} \eta^{\prime}\left(y_{g}^{*}+y_{n}^{*}\right)<\theta_{g} \eta^{\prime}\left(y_{g}^{*}+y_{n}^{*}\right)=1,
\end{aligned}
$$

and so the first-order condition for $y_{n}^{*}$ can never be satisfied for an interior solution. This implies that under government ownership $y_{g}^{*}>0$, and $y_{n}^{*}=0$. Consider NGO ownership now. The firstorder conditions are

$$
\begin{aligned}
\frac{\theta_{n}+\theta_{g}}{2} \eta^{\prime}\left(y_{g}^{*}+y_{n}^{*}\right)+\frac{\left(\theta_{g}-\theta_{n}\right)}{2} \lambda \eta^{\prime}\left(\lambda y_{g}^{*}+y_{n}^{*}\right) & =1 \\
\theta_{n} \eta^{\prime}\left(y_{g}^{*}+y_{n}^{*}\right) & =1 .
\end{aligned}
$$

Since $\left(\theta_{n}+\theta_{g}\right) / 2>\theta_{n}$, we conclude that even in this case $y_{g}^{*}>$ 0 and $y_{n}^{*}=0$. Finally, we want to compare $y_{g}^{*}$ under government and NGO ownership. Recall that by Assumption $1 B_{1}^{g}\left(y_{g}, y_{n}\right)>$ $B_{1}^{n}\left(y_{g}, y_{n}\right)$. In this case, given that $y_{n}=0$ in equilibrium under both ownership structures, this assumption translates to $\eta^{\prime}(y)>$ 
$\lambda \eta^{\prime}(\lambda y)$ for all $y$, or, $\lambda \eta^{\prime}(\lambda y)$ is nondecreasing in $\lambda$ on $[0,1] .^{30}$ Hence government ownership is optimal, and only the government invests in equilibrium. The proof for the case $\theta_{n}>\theta_{g}$ is identical. For $\theta_{n}=\theta_{g}$ it does not matter who the owner-cuminvestor is.

QED

\section{Proof of Proposition 6}

Under g's ownership the investment levels are

$$
y_{g}^{g}=f\left(\theta_{g} a_{g}\right) \text { and } y_{n}^{g}=f\left(\left(\theta_{g} \frac{1-\lambda_{n}}{2}+q \theta_{n} \frac{1+\lambda_{n}}{2}\right) a_{n}\right),
$$

while under n's ownership they are

$$
y_{g}^{n}=f\left(\left(q \theta_{g} \frac{1+\lambda_{g}}{2}+\theta_{n} \frac{1-\lambda_{g}}{2}\right) a_{g}\right) \text { and } y_{n}^{n}=f\left(\theta_{n} a_{n}\right) .
$$

If $q<1$, the valuation of a party is lower when the other party is the owner and chooses project design, compared with when she is the owner for a given level of $y_{n}$ and $y_{g}$. This affects her investment incentives negatively. If $q$ is small enough, this effect can overturn our results concerning who should be the owner. Thus, even if $\theta_{g}>\theta_{n}$, it may be that $y_{n}^{n}>y_{n}^{g}$ when $q$ is small (so long as $\lambda_{n}$ is not too low). This implies that, if $a_{n}$ is high relative to $a_{g}$, it may be optimal to make $n$ the owner.

QED

\section{LONDON SCHOOL OF ECONOMICS}

UNIVERSITY OF CHICAGO

\section{REFERENCES}

Aghion, Philippe, and Jean Tirole, "Formal and Real Authority in Organizations," Journal of Political Economy, CV (1997), 1-29.

Bergstrom, Ted C., "When Does Majority Rule Supply Public Goods Efficiently?" Scandinavian Journal of Economics, LXXXI (1979), 216-226.

Bratton, Michael, "The Politics of Government-NGO Relations in Africa," World Development, XVII (1989), 569-587.

Chiu, Y. Stephen, "Noncooperative Bargaining, Hostages, and Optimal Asset Ownership," American Economic Review, LXXXVIII (1998), 882-901.

Clark, John, "The State, Popular Participation and the Voluntary Sector," World Development, XXIII (1995), 593-601.

De Meza, David, and Ben Lockwood, "Does Asset Ownership Always Motivate Managers? Outside Options and the Property Rights Theory of the Firm," Quarterly Journal of Economics, CXIII (1998), 361-386.

Duggan, Mark, "Hospital Ownership and Public Medical Spending," Quarterly Journal of Economics, CXI (2000), 1343-1374.

30. For example, this condition is satisfied by $\eta(y)=y^{\gamma}$, where $\gamma \in(0,1)$ or $\eta(y)=\log y$. 
Farrington, John, and Anthony Bebbington, Reluctant Partners: NGOs, the State and Sustainable Agricultural Development (London: Routledge, 1993).

Farrington, John, and David J. Lewis, Non-Governmental Organizations and the State in Asia: Rethinking Roles in Sustainable Agricultural Development (London: Routledge, 1993).

Fiszbein, Ariel, and Pamela Lowden, Working Together for a Change: Government, Civic and Business Partnerships for Poverty Reduction in Latin America and the Caribbean (Washington, DC: Economic Development Institute of the World Bank, 1999).

Glaeser, Edward L., and Andrei Shleifer, "Not-For-Profit Entrepreneurs," Harvard Institute of Economic Research Working Paper No. 1852, 1998.

Grossman, Sanford, and Oliver Hart, "The Costs and Benefits of Ownership: A Theory of Vertical and Lateral Integration," Journal of Political Economy, XCIV (1986), 691-719.

Hart, Oliver, Firms, Contracts and Financial Structure (Oxford: Oxford University Press, 1995).

Hart, Oliver, and John Moore, "Property Rights and the Theory of the Firm," Journal of Political Economy, XCVIII (1990), 1119-1158.

Hart, Oliver, Andrei Shleifer, and Robert Vishny, "The Proper Scope of Government: Theory and an Application to Prisons," Quarterly Journal of Economics, CXII (1997), 1119-1158.

Klibanoff, Peter, and Jonathan Morduch, "Decentralization, Externalities, and Efficiency," Review of Economic Studies, LXII (1995), 223-247.

Kremer, Michael, and Anedrei Sarychev, "Why Do Governments Operate Schools?" mimeo, Harvard University, 1998.

Malena, Carmen, "Working with NGOs: A Practical Guide to World Bank-NGO Operational Collaboration," Operations Policy Department, the World Bank, 1995.

Mliga, Gilbert R., "Decentralization and the Quality of Health Care," in David K. Leonard, ed., Africa's Changing Markets for Human and Animal Health Services (London: Macmillan, 2000).

Rajan, Raghuram, and Luigi Zingales, "Power in a Theory of the Firm," Quarterly Journal of Economics, CXIII (1998), 387-432.

Rasul, Imran, "Children as a Household Public Good," typescript, London School of Economics, 2000.

Riddell, Roger C., and Mark Robinson, Non-Governmental Organizations and Rural Poverty Alleviation (Oxford: Clarendon Press, 1995).

Segal, Ilya, and Michael Whinston, "Exclusive Contracts and Protection of Investments," mimeo, Stanford University, 1998.

Sen, S., "The Non-Profit Sector in India," in Helmut K. Anheier and Lester M. Salamon, eds. The Non-Profit Sector in the Developing World: A Comparative Analysis (Manchester, UK: Manchester University Press, 1998).

Shleifer, Andrei, "State versus Private Ownership," Journal of Economic Perspectives, XII (1998), 133-150.

United Nations, Interagency Committee on Integrated Rural Development for Asia and the Pacific (New York: United Nations, 1992).

United Nations Development Program, Human Development Report (New York: Oxford University Press, 1993).

Weiss, Yoram, and Robert Willis, "Children as Collective Goods in Divorce Settlements," Journal of Labor Economics, III (1985), 268-292.

World Bank, Bureaucrats in Business: The Economics and Politics of Government Ownership (Oxford, UK; and New York: Oxford University Press, 1995).

_- "Consultative Meeting on Partnerships: Joining Hands with Government and Non-Government Development Organizations and Local Communities," The NGO Unit, 1998.

World Development Report, The State in a Changing World (New York: World Bank and Oxford University Press, 1997). 